$\$$ sciendo

\title{
On the Ontology of Relations
}

\author{
Guido Imaguire
}

Federal University of Rio de Janeiro

Disputatio Vol. 4, No. 34

December 2012

DOI: 10.2478/disp-2012-0028

ISSN: 0873-626X 


\title{
On the Ontology of Relations
}

\author{
Guido Imaguire \\ Federal University of Rio de Janeiro and LanCog Group
}

BIBLID [0873-626X (2012) 34; pp. 689-711]

In A Theory of Universals (1978) Armstrong regretted that the interest around the dispute on internal and external relations had died away with the decline of Absolute Idealism. Further, in consequence of this, advances in the ontology of relations have not been comparable with the great advances in the topic of the logic of relations. Since Armstrong wrote this, some time has passed by, but the situation is essentially unchanged. Some investigation concerning relations has been done, but I think that many of them were contaminated by old prejudices.

This paper is intended as a contribution to minimize this gap. I will defend and argue in favour of some positive claims concerning the ontological status of relations. The main topics - and corresponding sections - of this paper are (1) irreducibility, (2) externality and (3) reality of relations. Thus, my topics exactly coincide with Russell's main topics in the theory of relations. But my purpose here is not an exegetical investigation of the controversy between classical authors like Russell, Bradley and Leibniz. ${ }^{1}$ I will just offer some cursorily historical remarks in order to introduce the questions, but then I will propose some (I hope) original theses and arguments.

\section{The irreducibility of relations}

Aristotle was the first to defend the reducibility of relations. He said in his Categories that, whenever two (or more) substances are related, this is to be explained by means of certain monadic properties or

\footnotetext{
${ }^{1}$ Many scholars did such an analysis; see e.g. Clautenbaugh (1973), Mugnai (1992) and my own (2006).

Disputatio, Vol. IV, No. 34, December 2012
} 
accidents inhering in the relata. ${ }^{2}$ Many scholastic and modern philosophers followed him in this. But, like Russell (and some medieval thinkers, in particular Albert the Great and John Duns Scotus), I believe this old tradition to be wrong. Some relations are reducible, some irreducible - that is my first thesis.

The topic of reducibility of relations has been usually treated as a semantical issue concerning relational propositions. Russell proposed its standard formulation: can all $a R b$ propositions be reduced to $S-P$ propositions? But the term "reduction" can also be interpreted in an (more original) ontological sense. And since my interest here does not concern semantics, I propose an ontological reformulation: do all relational facts supervene upon monadic facts? Actually, the semantical and the ontological questions must be not only distinguished, but clearly separated. Ontology does not always have to follow semantics. Indeed, after proposing a test for deciding which relations are ontologically reducible and which not, we will see that propositional reducibility does not imply ontological reducibility, nor the other way round.

Let us first see a misguided route. Many contemporary authors (e.g. Mugnai 1992: 96, Horstmann 1984) have suggested that relations are reducible if and only if they are symmetric. They are clearly influenced by Russell's argument ${ }^{3}:$ if $R$ in $a R b$ were symmetric, than $R\{a, b\}$ would be a correct analysis (the predicate " $R$ " is applied to the set $\{a, b\})$. In this case we do not need the ordered pair $(a, b)-$ the simple set $\{a, b\}$ would do. A pair, insofar as it is ordered, is "implicitly relational", i.e. it entails a hidden relationality (something like " $a$ comes before $b$ ") - so thought Russell and his followers.

Now, I think that this kind of reduction is a merely curious "logical" feature of symmetric relations. This might be relevant for a propositional reduction, but has no ontological relevance. (Actually,

${ }^{2}$ In Metaphysics Aristotle seems to relativize this doctrine claiming that "there are relational situations (such as Simmias's thinking about Socrates) in which substances are related not in virtue of a pair of accidents, but rather in virtue of a single accident possessed by just one of the substances." See Stanford Encyclopedia of Philosophy http://plato.stanford.edu/entries/relations-medieval.

${ }^{3}$ Russell used this argument many times, see e.g. Principles of Mathematics $\S$ 426, The Philosophy of Leibniz § 10, Logical Atomism p. 335, My Philosophical Development p.67. 
I tend to think that this is more a notational than a real "logical" feature.) Take the case of Peter and his son Paul. Peter was first, say at $\mathrm{t}_{1}$, taller than Paul. Along the years, Paul grew and became, say at $\mathrm{t}_{3}$, taller than Peter. Since is taller than is an asymmetric relation, it must be irreducible according to Russell's criterion. But there is certainly a moment, say $t_{2}$, in which Peter and Paul had exactly the same height. Now, is as tall as is a symmetric relation, and, according to this criterion, it must be reducible. The consequence of this kind of reasoning would be that the particular height-relation between these two men changes its status through time: it is sometimes reducible (and so, according to Russell, internal and unreal) and sometimes irreducible (and so external and real) ${ }^{4}$. But this certainly sounds very odd for any philosopher with a robust sense of ontology. Paul's height relative to Peter (or any other object) can change through time, but the relation cannot change its ontological status (reducibility, reality or externality). This reasoning becomes even more absurd when we interpret - as usually is done - "internality" by means of "essentiality": Paul was at $\mathrm{t}_{1}$ essentially (internally) smaller than Peter, then, at $t_{2}$, Paul became accidentally (externally) as tall as Peter, and, finally, at $t_{3}$ Paul became essentially taller than Peter. This is simply metaphysical non-sense. There cannot be diachronic change in the essential properties of things. Thus, I conclude that symmetry is not an adequate criterion for deciding the question of ontological reducibility.

Nevertheless, I think that Russell was right in defending that some relations are reducible, and others not. But the reason for this difference is not a curious logical feature like symmetry, but an ontological one. Rescher (1967:72) proposed a general and very useful test for deciding the question on the propositional reducibility of relations. In a simplified formulation, the semantical reducibility test (SRT) says:

(SRT) The relation $R$, which subsists between two particulars $a$ and $b$, is reducible if and only if there exist monadic predicates $P_{P}$, $P_{2}, \ldots, P_{n}$ and $Q_{1} Q_{2}, \ldots, Q_{n}$, such that $P_{1}(a) \wedge P_{2}(a) \wedge \ldots \wedge P_{n}(a) \wedge Q_{1}(b)$ $\wedge Q_{2}(b) \wedge \ldots \wedge Q_{n}(b)$ determine completely the truth established

${ }^{4}$ For Russell, reducibility, externality and reality are (at least extensionally) equivalent. 
by $a R b .^{5}$

Two remarks are important here. First, the predicates $P_{1}-P_{n}$ and $Q_{4}-Q_{n}$ in the SRT should obviously not be explicitly or implicitly relational like "[...Rb]" (i.e. something like "to be taller than $b$ "). When one accepts this kind of relational predicate the reduction of every relation becomes trivially possible. Thus, impure monadic predicates (predicates with an implicit reference to some particular) must be excluded. Second, ST is clearly dependent on the language we use: the "existence of predicates" is at stake. And the existence of monadic predicates depends, of course, on our arbitrary act of introducing such predicates in our language. But in this case our ontology would be trivially dependent on linguistic decisions. Thus, following the general device proposed above for separating ontological and semantical reduction, I suggest a purely ontological version of the reducibility test (ORT):

(ORT) The relation $R$, which subsists between two particulars $a$ and $b$, is reducible if and only if $a$ has the properties $P_{1}, P_{2}, \ldots, P_{n}$ and $b$ has the properties $Q, Q, \ldots, Q$, such that the conjunctive fact $P_{I}(a) \wedge P_{2}(a) \wedge \ldots \wedge P_{n}(a) \wedge Q_{1}(b) \wedge Q_{2}(b) \wedge \ldots \wedge Q_{n}(b)$ completely determines the fact $a R b$, i.e. $a R b$ supervenes the conjunctive fact with monadic properties. ${ }^{6}$

The basic insight of my ORT is the - I hope: reasonable - supposition that reducibility can be defined by means of supervenience. But note: I define reducibility by means of supervenience, but I do not identify reducibility with supervenience simpliciter. As we will see below, not all supervenient relations are also reducible. Again, two remarks are important here: First, similarly to our first remark

\footnotetext{
${ }^{5}$ Parkinson (1965: 45) suggest a stronger (and implausible) variant of this test, in which only the predicates of one leg of the relation $-P_{1}(a) \wedge P_{2}(a) \wedge \ldots \wedge$ $\mathrm{P}_{\mathrm{n}}$ (a) - could sustain completely the truth established by $a R b$.

${ }^{6}$ I am not committed to - and will not argue for - the existence of complex facts in addition to simple facts. The phrase "complex fact $P_{1}(a) \wedge P_{2}(a) \wedge \ldots$... could simply be paraphrased by "the fact that $P_{I}(a)$ and the fact that $P_{2}(a)$ and the fact that...". Further, since this criterion also holds for not actually obtaining facts, the phrase "states of affairs" would probably be more adequate, but I will simply use "fact" for the sake of simplicity.
} 
above concerning impure predicates, in the ORT impure monadic properties (implicitly relational properties) must be excluded in order to avoid trivial reduction. Second, in ORT I deliberately avoid talking in terms of "existence" or "non-existence" of properties, as was the case in SRT. The question on the existence of properties is connected with some more difficult metaphysical questions like the realism versus nominalism dispute, criteria for deciding which properties really exist (quantification over properties - by Quine or their occurrence in natural laws - by Armstrong, etc.) that are to be avoided in this section. I will come back to this later. Therefore, I will simply take all ordinary properties to be genuine properties in the following discussion.

In general, we say that an entity B supervenes upon an entity A if and only if it is impossible that A should exist and B not exist, where A is possible ${ }^{7}$ (this last restriction, of course, is introduced in order to avoid trivialization - for the rest of this paper I suppose it implicitly). For the particular case of relations, we can formulate:

The relation $R$ in $a R b$ is supervenient when the relational fact $a R b$ supervenes upon facts $F_{l}, \ldots, F_{n}$ if and only if it is impossible that $F_{1}, \ldots, F_{n}$ obtain and $a R b$ does not obtain.

In this formulation, I say $R$ "in" $a R b$ is supervenient because we cannot suppose without more arguments that, given that the fact $a R b$ is supervenient in our sense, the relation $R$ is supervenient simpliciter, i.e. in all other facts where it occurs (it could be not supervenient in another fact $c R d$ ). Alternative standard formulations for supervenience will do as well for our purposes: "the facts $F_{l}, \ldots, F_{n}$ entail $a R b$ ", or "all $F_{l}, \ldots, F_{n}$-worlds are $a R b$-worlds", etc.

Now, how can we decide when a relation is supervenient in this sense? The first step here is the recognition of the huge variety of kinds of relations. Actually, I think that the recognition and observance of this variety is the most urgent methodological imperative in ontology of relations today. I am convinced that some philosophical theses about relations are misguided because of the failure in observing this variety. To put it in Wittgenstein's words “A main cause of philosophical disease - a one-sided diet: one nourishes one's think-

\footnotetext{
${ }^{7}$ This definition was proposed by Armstrong in (1997: 11)
} 
ing with only one kind of example" (PI § 593). This kind of "one-sided diet" is specially striking when we compare the fanciless examples used in analyses of relations with the rich variety of examples used in analysis concerning particulars and monadic properties.

Relations vary in many different ways. For deciding the test of reducibility it is helpful to point out the variety of ontological "orders" (still in an ambiguous sense) of relations and introduce a notation for codifying these orders:

$\mathrm{R}^{0-0}$ relations that obtain between objects (e.g. $a$ loves $b, a$ sees $b, a$ is bigger than $b$ )

$\mathrm{R}^{1-1}$ relations that obtain between 1 -order properties of objects (e.g. the wisdom of $a$ is greater than the wisdom of $b$ )

$\mathrm{R}^{0-1}$ relations that obtain between an object and a 1-order property of an object

(e.g. $a$ admires the wisdom of $b)^{8}$

$\mathrm{R}^{1-0}$ relations that obtain between a 1-order property of an object and an object

(e.g. the weight of this box surprised me)

$\mathrm{R}^{2-2}$ relations that obtain between 2-order properties or 2-order relations of objects (e.g. the beauty of the colour of $a$ is greater than the beauty of the colour of $b$ ).

$\mathrm{R}^{0-2}$ relations that obtain between an object and a 2-order property or relation of objects (e.g. $a$ admires the beauty of the colour of b).

and so on...

This classification is ambiguous: it allows a semantical and an ontological interpretation. I think that not all $\mathrm{R}^{0-0}$ relations in a semantical sense are also first-order $R^{0-0}$ relations in a full ontological sense. Take e.g. " $a$ is bigger than $b$ ": in a semantical sense, this is a $R^{0-0}$ relation: $R$ has entities of type 0 as relata; " $a$ " and " $b$ " are singular terms. But, ontologically, the fact that $a$ is bigger than $b$ supervenes upon the fact that $a$ has the height $\mathrm{S} 1$, and $\mathrm{b}$ has the height $\mathrm{S} 2$ (and $\mathrm{S} 1>\mathrm{S} 2$ ).

\footnotetext{
${ }^{8}$ We must distinguish between $\mathrm{R}^{0-1}$ and $\mathrm{R}^{1-0}$ because relations are not always symmetrical. Thus $\mathrm{R}^{0-1}$ is a relation from an object to a property and $\mathrm{R}^{1-0}$ a relation from a property to an object.
} 
Again, language is not always a good guide to ontology. (There is a second ambiguity: my distinction of orders should not be confused with the Aristotelian distinction of orders - I will come back to this later.) In any case, the relevant interpretation for deciding reducibility is the ontological one. My point concerning reducibility is this: some relations supervene upon monadic properties of related things, others do not. Supervenient relations are ontologically dependent on the properties of things, and their holding or not is fully determined by the things having properties. Examples of supervenient relations are:

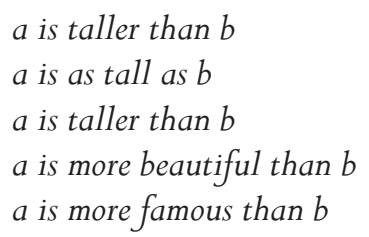

Note that, from a semantical point of view, these are all $\mathrm{R}^{0-0}$ relations - but, and this is my point, not from an ontological point of view. These relations do not hold "directly" between particulars, but between properties of particulars. Take the first example again: the fact that $a$ is taller than $b$. An ontological analysis of the corresponding fact should be something like: $a$ has height $S 1 \wedge b$ has height $S 2 \wedge$ $S 1>S 2$. Thus, ontologically speaking, is taller is an $\mathrm{R}^{1-1}$ relation. The fact that $a$ is taller than $b$ is entailed in the conjunctive fact that $a$ is $\mathrm{S} 1 \wedge b$ is $\mathrm{S} 2$ (e.g. there is no possible world in which $a$ is $2 \mathrm{~m}$ tall, $b$ is $1 \mathrm{~m}$ tall and the relational fact that $a$ is taller than $b$ does not hold). ${ }^{9}$

Of course, not all properties are objectively measurable. But this does not imply that, in these cases, the relation cannot supervene upon properties. Take e.g. beauty: if $a$ is beautiful and $b$ is ugly, then $a$ is more beautiful than $b$. In such cases, objective analysis becomes difficult, but this does not undermine supervenience.

In all these cases, the particulars hold the corresponding relation

\footnotetext{
${ }^{9}$ Russell would certainly say, contrary to me, that this analysis shows that the relation is taller than is not reducible: in the analysans another relation $(S 1>S 2)$ occurs, thus the relation did not "disappear". This makes it clear that my sense of "reducibility” does not correspond to Russell's sense.
} 
just because they instantiate certain properties. The properties instantiated by the particulars necessitate the relation. The properties can be essential or accidental to the particulars, but they are a necessary and sufficient condition for the holding of the relation.

On the other hand, examples of non-supervenient relations are:

$$
\begin{aligned}
& a \text { loves } b \\
& a \text { is married to } b \\
& a \text { is the father of } b \\
& a \text { kills } b \\
& a \text { kisses } b
\end{aligned}
$$

These are $\mathrm{R}^{0-0}$ relations from both semantical and ontological points of view. There is no property of $a$ or $b$ that entails the love of $a$ for $b$. Maybe $a$ loves some property of $b$, but this is a different fact from $a$ loves $b$ (in that case, we would have $\mathrm{R}^{0-1}$ instead of $\mathrm{R}^{0-0}$ ). Maybe $a$ loves $b$ because of some property of $b$, but this is, again, another (I suppose complex) fact: it is a fact that explains why $a$ loves $b$. Maybe $a$ is married to $b$ only because $b$ has the property of being rich, but this does not mean that it is no property of $a$ which is married to any property of $b$, but $a$ is married to $b$. Note that some relations are dependent on some properties: $a$ is father of $b$ only if $a$ instantiates the property to be male, $a$ can kill $b$ only if $b$ instantiates the property to be alive, etc. In these cases, the properties are necessary conditions for the relations, but they do not necessitate the relation. A male does not have to be father, a living organism does not have to be killed, and so on. The same is valid for all levels of relations. Take the $\mathrm{R}^{0-1}$ relation

$$
\begin{aligned}
& a \text { admires the wisdom of } b \\
& a \text { envies the wealth of } b
\end{aligned}
$$

These are clearly non-supervenient relations: there is neither a property of $a$ nor a property of $b$ that necessitates the relation of admiration (not even $b$ 's wisdom). Similarly, there is neither a property of $a$ nor a property of $b$ that necessitates the relation of envy ( not even $b$ 's wealth). A relation is reducible if and only if both sides are grounded in properties of the terms, i.e. the relation must be "both-sided" supervenient. 
All this sound as if reducibility of relations were identified with supervenience simpliciter, but this is not the case. In the proposed test for reducibility, it is required that $a R b$ supervene upon the complex fact with monadic properties, while in the definition of supervenience for relations, it is not required that facts $F_{1}, \ldots, F_{n}$ must be monadic. This is so because it seems possible that a given relational fact $F_{1}$ supervenes upon two facts $F_{2}$ and $F_{3}$, such that one of them (or both) is relational and irreducible. Take e.g. the relation is-brother-of. I think the relational fact $a$ is brother of $b$ supervenes other relational facts ( $a$ is a child of $\mathrm{x}$ with $\mathrm{y} \wedge b$ is a child of $\mathrm{x}$ with $\mathrm{y}$ ), and these last relational facts are not supervenient and irreducible. If this is correct, is brother $o f$ is a case of a supervenient but irreducible relation, i.e. it is not reducible to exclusively monadic facts. Therefore, reducibility and supervenience, at least for relations, are not equivalent. One might ask: if this is true, how should we decide that a relation is reducible or irreducible until the "whole analysis" to ultimate basic facts is done?

Indeed, the question on a complete analysis (of facts, of propositions, or whatever) seems to lead us into deep trouble. How can we decide whether at a given moment we achieved the terminal level of the most basic facts? The proposed criterion for deciding reducibility of relations seems to be committed to the assumption that facts are not infinitely analysable. Actually, I believe this to be a plausible assumption. The possibility of an infinite analysis displeases most philosophers. Of course, there is, insofar as I can see, no knock-down argument against it. Thus, it seems that a relational fact $F_{1}$ can be (completely) reduced to a conjunction of exclusively monadic facts $F_{1}, \ldots, F_{n}$, but that some (at least one) of these facts, in their turn, supervene on even more basic relational facts, and so on. In this case, a conclusive decision about reducibility of relations seems unachievable. But even if there were such infinite complex facts, my ORT offers a conclusive criterion at least for the positive cases, i.e. that a certain relational fact is reducible. Note that ORT does not require that the constituents of the complex fact $P_{1}(a) \wedge P_{2}(a) \wedge \ldots \wedge P_{n}(a) \wedge$ $Q_{+}(b) \wedge Q_{2}(b) \wedge \ldots \wedge Q_{n}(b)$, that necessitate the fact $a R b$, must be ultimate. For a given relation $R$ to be reducible, it suffices that at "some" level a full eliminative conjunction of monadic facts is achievable. In this case, we can conclude that $R$ is reducible. What we cannot conclude, of course, is that all relations are reducible (in a linguistic 
formulation: we cannot conclude that a complete monadic "worlddescription" is possible). But, again, by the plausible assumption that analysis is not infinite, we have a definitive criterion for both cases of reducibility and irreducibility.

It is important to stress that this ontological distinction between reducible and irreducible relations does not coincide with the Aristotelian distinction between first order and second order attributes. ${ }^{10}$ To say that a relation is grounded on the properties of things does not imply that this relation is, in the Aristotelian sense, a second-order relation. When Socrates and Plato are white, the fact that Socrates and Plato have the same colour entails the reducible relation to have the same colour. But I think Aristotle would (correctly) consider to have the same colour (different from is the same colour as!) a relation between things (and not between properties of things). Reducible relations in my sense are, first, ontologically dependent on properties of things, i.e. the properties are a necessary condition for the supervenient relation. Second, the relations are always present when the corresponding properties are instantiated in the relata, i.e. the instantiation of the relevant properties is a sufficient condition for the subsistence of the supervenient relation. These relations are, to use Armstrong's terminology (1997: 12), an "ontological free lunch" - they are not an addition of Being.

Of course, it is not easy to decide for every relation whether it is supervenient to other facts or not: is the relation is-20m-distant-from a non-supervenient relation or a relation that supervenes upon the monadic properties position-of-x and position-of-y? This depends, of course, on our conception of space. Suitable ontological analyses are required in many particular cases; in particular, spatial and temporal relations deserve a special examination.

The very natural thesis defended here has been overlooked by many authors simply because they restrict their analysis to a too small set of examples of relations, instead of analysing their great variety. Mugnai e.g. (1992: 22) comes very near to my criterion. He tells us that for Leibniz veritates relationum videntur esse reflexivae, i.e.

truths corresponding to relations are properly speaking 'second-order

${ }^{10}$ This could be one reason why Aristotle was unable to recognize different degrees of reality of relations. 
truths', which, so to say, supervene other truths. The relationship of similarity between Socrates and Plato, for example, happens at the movement when Socrates and Plato are both white, but this simply means that the truth of the proposition: 'Socrates is similar to Plato' is based on the truth of the two assertions: 'Socrates is white' and 'Plato is white', and the whole proposition comes into being when one reflects on these assertions.

Of course, the truth of "Socrates is similar to Plato" is grounded on the truth of "Socrates is white" and "Plato is white". Thus, this relation can be considered reducible. But on which monadic propositions is the truth of "Socrates loves Plato" based? I cannot see any monadic propositions and no distribution of monadic properties in the world that could ground its truth.

\section{On the internality of relations}

One classical dispute between the pioneers of analytic philosophy and the absolute idealists concerned the internality vs. externality of relations. Absolute idealists, at least according to the standard interpretation, defended that all relations are internal (e.g. F. H. Bradley in 1897), while analytic philosophers (in particular Russell) defended that some relations are external. But it is not clear what these authors mean by the phrases "internal" and "external". In $M y$ Philosophical Development (1959) Russell gave us some hints about how he understood the thesis of internalism of relations:

He [Leibniz] says that, if a man living in Europe has a wife in India and the wife dies without his knowing it, the man undergoes an intrinsic change at the moment of her death. This is the kind of doctrine that I was combating. (MPD: 42)

But it is also not clear how we should interpret the vague word "intrinsic" in this passage. Russell could hardly be combating the principle of identity according to which entities with different properties are different. If $x$ is a husband (and not a widow), and $y$ is a widow (and not a husband), then it is necessarily true that $x$ is different from $y$. It seems very plausible to suppose that the poor man of the story changed a property with the death of his wife. And Russell would certainly not deny that the wife in the story undergoes an intrinsic change at the moment of her death. In contemporary theory of properties, it is usual to distinguish between intrinsic and extrinsic prop- 
erties. Intrinsic properties are non-extrinsic, and extrinsic properties are properties that a thing has in virtue of its relation to another (at least one other) thing, i.e. they are implicitly relational - in the example, to be a husband and to be a widow are certainly extrinsic. But this distinction was not explicitly made by Russell. And if this were what Russell meant, his claim would be trivial - of course, the change of the man was a change in virtue of something else, namely the death of his wife. Thus, his intuition must be based on a distinction between "somehow" more relevant and less relevant properties and relations. The most obvious distinction of this sort is the classical distinction between essential and accidental properties. Actually, in some passages Russell explicitly introduced the notion of "essence":

"If A and B are related in a certain way", it may be said, "you must admit that if they were not so related they would be other than they are, and that consequently there must be something in them which is essential to their being related as they are." (MDP: 46, my emphasis)

In any case, I will discuss in this section the status of relations concerning their essentiality. Since Russell was not a friend of the notion of substance and essentialism, I suppose he would not be happy about this decision. His usage of "essential" in this passage is probably only a façon de parler. But this should not worry us - our aim is systematic and not exegetical. After all, this was certainly Moore's original usage. In his "External and Internal Relations" (1919) he characterized internal relations modally: internal relations are essential to their relata.

I will defend two theses in this section:

(i) there are some (at least "impure" or "supervenient") essential relations, and

(ii) the question of essentiality (internality) is independent of the question on reducibility or irreducibility of relations (at least in the case that origin essentialism is correct).

Thesis (i) is, once one accepted essential properties, in some sense trivial. If there are essential properties at all, this is a difficult question I cannot investigate here. I will simply presuppose some kind of orthodox (Kripkean) essentialism in the following. Thesis (ii) is a more substantive thesis. It is intended as a criticism of Russell's (and 
others') supposition that reducibility is equivalent to internality (as well irreducibility to externality).

The overwhelming majority of examples of essential properties discussed in literature are monadic and not polyadic. As far as I can see, the most relevant case of an essential relation is the origin essentialism suggested by Kripke (1972: 112f), according to which if $a$ is the mother of $b, b$ is essentially son of $a$ (no person could have another mother than he or she actually has). And it is not surprising that this example of an essential feature is much more controversial than its monadic rivals. It is more intuitive to suppose that the existence of an entity depends on one of its monadic "constitutive" properties, than on something "external" as a relation that this entity holds with another entity. A "free floating" Socrates in an empty universe without any relations to other things (even without his mother) may sound strange, but less strange than a non-human Socrates. Concerning origin essentialism Robertson (1998) points out that both the origin essentialist of an artefact (that this table should be made of this very hunk of matter) and the origin essentialist of living organisms (that this organism must be developed from this very collection of propagules) are in trouble for they cannot respect their own essentialist intuition that a limited variation of the origin of a given thing is possible. It both cases, origin essentialism seems to be based on mereological intuitions: one thing cannot be construed of completely different constituent parts. The egg and the sperm are built into the new organism as essential parts of it. In the following I will suppose origin essentialism to be correct.

Now, when one is willing to assume a more tolerant view about what relations exist -i.e. not denying that "impure" or supervenient relations are genuine relations - we obtain an easy strategy for defending the existence of essential relations. We could simply construct essential relations from essential (monadic) properties: when to be a human being is an essential property of both Socrates and Plato, as most think they are, then to belong to the same species as is an "impure" essential relation between them. I call this relation "impure" because it entails an implicit reference to a monadic property. Actually, the essential character of this relation is only derived from a monadic property. One may object that this relation is not really essential, since one of them, say, Plato, could have not existed. In this 
case, Socrates would not belong to the same natural kind as Plato. I think this to be clearly wrong, because Plato is essentially a human being - independent of his existence. On the contrary, his very existence depends on being human. In all possible worlds in which he exists, he is human, and in all possible worlds in which he does not exist, he is, in some sense, human too. It is not the case that, in these possible worlds in which he does not exist, he is something else, say a worm. Thus, independent of his existence or not, independent of which possible world we take, Socrates always belongs to the same natural kind as Plato.

Whether such artificially constructed relations are respectable entities depends on how tolerant we are in our ontology. Of course, these relations are, according to my own criterion reducible, insofar as they are simply grounded in monadic properties. Just as most philosophers are not willing to accept that every predicate express a genuine property, so many may reject such relations as to belong to the same natural kind as. But at least (i) can be so far concluded: there are impure reducible essential relations.

Let us now think about the relation between essentiality and irreducibility. Some contemporary authors are already persuaded by Russell and think that internality (here: essentiality) is the same as (at least coextensive with) reducibility. See for example this passage by Heil (2009: 315):

Following the medieval thinkers, we could say that internal relations are "founded" on monadic (non-relational) features of their relata: when an internal relation holds, it holds in virtue of non-relational features of whatever it relates.

And, concerning external relations, he continues

An external relation, $\mathrm{R}$, holds between objects $a$ and $b$, in virtue of $a$ 's being $\mathrm{F}$ and $b$ 's being $\mathrm{G}$ ( $\mathrm{F}$ and $\mathrm{G}$ being non-relational properties of $a$ and $b)$. [...] Further, the initial breezy characterization of internal relations, can now be seen to apply quite generally: if you have the relata, you have the relations. (Heil 2009: 317)

I think this (in particular the general form "quite generally") to be clearly wrong: there is neither a necessary connection between internality (essentiality) and irreducibility nor between reducibility (to be "founded" on monadic properties) and externality of relations. Heil's failure to see the independence of both aspects lies probably 
in the meagre diet of examples he took, namely the internality of six being greater than five and the external monadic founded fact of Simmias being taller than Socrates. I am convinced that is greater than in six is greater than five is internal not because it is grounded in monadic properties of five and six, but simply because pure arithmetical properties and relations are always essential (or internal). And the relation is taller than in Simmias is taller than Socrates is external not because it is not founded on monadic properties, but because these monadic properties (the height of Simmias and the height of Socrates) are not essential. Thus, I propose that, when $a$ is essentially $F$ and $b$ is essentially $\mathrm{G}$ and the relation $\mathrm{R}$ supervenes $\mathrm{F}$ and $\mathrm{G}$, then $\mathrm{R}$ is internal to $a$ and $b$ (this was e.g. the case of belong to the same species). When $a$ is not essentially F or $b$ is not essentially G (or both), then the relation $\mathrm{R}$ that supervenes $\mathrm{F}$ and $\mathrm{G}$ is external to $a$ and $b$.

Of course, first one has to obtain clarity about which relations are really essential (if any). Let us, for the sake of the argument, suppose that origin essentialism is correct. Thus, $a$ is son of $b$ is an internal relation (to $a$, not to $b$ ). Remember that thesis (ii) has a hypothetical form: when origin essentialism is correct, the question of essentiality (internality) is independent of the question on reducibility or irreducibility of relations.

The easier strategy for arguing for the independency of reducibility and internality is to give some counter-examples. A very plausible example of an accidental relation is to love. It can be hardly denied that although $a$ actually loves $b, a$ could not simply love $b$ without damage to its existence or identity. Nevertheless, to love is, according to our ORT, an irreducible relation. When a loves $b$, this relation is not supervenient to any property of $a$ or $\mathrm{b}$. Thus, there are irreducible accidental relations. Irreducibility does not imply internality.

Take now the relation is heavier than in $a$ is heavier than $b$ (where $a$ and $b$ are, say, human beings). It is clear that this relation can be reduced to monadic properties in the sense of ORT (a weighs $x \mathrm{Kg} \wedge$ $b$ weighs y $K g \wedge x>y$ ). Weight is not an essential property of a person, except, or course, for super-essentialism, for which every property is trivially essential. This is an example of a reducible accidental relation; thus, reducibility does not imply internality.

According to ORT, the relation to be son of is irreducible, for if $a$ is son of $b$, this is so not in virtue of some monadic properties of $a$ and 
$b$. Now, the relation is son of (to have these very parents) is considered an essential property of a person. Thus, there are internal irreducible relations; internality does not imply reducibility.

Take, on the other hand, another example of Kripke's (1972: 113114) for an essential property, namely to be made of. According to him, if this table is made of wood, we cannot say that this very table could, instead of wood, simply be made of ice water taken from the River Thames. A table made of ice from the river would not be this table. If this is correct, then the relation is made of the same substance $a s$ is an essential relation for two objects $a$ and $b$ (suppose, made from wood). Nevertheless, given our ORT, is made of the same substance as is a reducible relation, since the fact that table a is made of the same substance as table $b$ supervenes upon the monadic facts that $a$ is made of wood and $b$ is made of wood. Thus, there are relations that are both internal and reducible; internality does not imply irreducibility. To sum up, as (ii) claims: internality/externality and reducibility/irreducibility are independent ontological aspects of relations.

\section{Reality of relations}

In contrast to "existence", "subsistence" and "actuality", no definitions have been offered for the notions of "reality" and "unreality". It seems unclear what we mean when we say that something is real or unreal. In most cases, we use this notion in ontology in a more or less intuitive sense. Further, these terms seem not to qualify something in a positive, interesting way: Are there real and unreal things? I propose in this section two different approaches to the problem of reality, the traditional and the contemporary a posteriori one.

\subsection{The traditional approach}

According to this approach, reality is conceived by means of ontological independence. The more an entity is ontologically dependent on others, the more it is unreal. This approach has a long tradition. In scholaticism God was considered the ens realissimum just because He is absolutely independent of any other entity; Aristotelian substances were considered real (even if not "as" real as God) because they were independent of their attributes; these attributes, in their turn, were 
less real than substances because they were dependent on them, and so on. Fictions are ontologically weak because they are dependent on human creative thought. Following this reasoning, some scholastics conclude that relations have a very low ontological status, for their existence relies on the existence of many other entities: on the relata, on the properties of these relata and, worse, on a recognizing mind. Thus, when Plato and Socrates are similar (both are white), this similarity depends on Plato, Socrates, the whiteness of Plato, the whiteness of Socrates, and even on a mind that compares both. ${ }^{11}$

But some medieval thinkers tried to see a little bit more reality in relations. Ockham for example made a distinction between relationes reales and relationes rationis. While relationes rationis are dependent on an arbitrary decision of our intellect, like the relation between a word-sign and its meaning, relationes reales depend on the recognition of an intellect, but not on our arbitrary decision, like the relation between a mother and her son. Thus, Ockham did certainly not intend to reject the objective nature of the relationes reales. And when Leibniz says that relations are entia rationis, he neither intends them to be arbitrary creations of our intellect, like Ockham's entia rationis, nor to be mere fictional entities. Leibniz distinguished between entia rationis sine fundamento in re, like Pegasus, and entia rationis cum fundamento in re, like relations that subsist in actual facts. If David is father of Solomon, then the relation of paternity between David and Solomon is not a mere fiction in the sense that Pegasus is one.

But to say that relations have a fundamentum in re can still be considered a sign of ontological weakness: relations do not subsist in themselves. They need the relata in order to subsist - they are grounded in re. Indeed, in his letter to Des Bosses (17 fev 1711) Leibniz says that a relation without fundamentum is a self-contradictory notion. Relations are not ontologically independent and do not have independent "capacity of movement". They begin to subsist and end subsisting, but only insofar as their "ontological basis" - objects or properties of objects - allow or determine this. Thus, the thesis of

${ }^{11}$ In De Potentia, q. 8 ar. 1, ra 4 Thomas writes: "Relatio habet esse debilissimum, quod est eius tantum” and very similarly, so does Scotus in Super Praedicamenta (q. 25, 10): "Relatio inter omnia entia est debilissimum ens, cum est sola habitudo duorum, et ita minime est cognoscibilis in se" (quoted by Mugnai 1992:27) 
unreality of relations should be understood in the sense that relations are ontologically dependent, and not that they lack an objective nature. ${ }^{12}$ This insight seems to be present in natural intuition: Imagine a collection of many particulars organized in a hierarchical order by the ordering relation $R$. Now what would remain if we subtract all the particular things? An "empty order", an ordered structure without ordered things, is non-sense.

Now, what should we conclude? I do not think that all relations are mind-dependent. Most late scholars defended the objective nature of some relations, and this seems a plausible thesis. A knockdown argument against mind-dependence of any kind of entity cannot be given, nor for the particular case of relations. The best we can do, I suppose, is to follow contemporary metaphysicians and take natural science with all its relational concepts (causality, cross fertilization, chemical reactions, etc.) in order to see how objective relational descriptions of reality are. If we also take mathematics, the question seems even more evident: relations are not eliminable and, thus, objective. Of course, a radical idealist would not be impressed by this argument, but I suppose him to be unimpressed by any realist argument at all. The need of relational predicates does not imply the existence of an ontological correlate.

In any case, when my argument in the first section is sound, there are relations that are irreducible to monadic properties. When $a R b$ is a relational fact that does not supervene upon more basic monadic facts, then we should conclude that $R$ is not ontologically dependent on monadic properties. At least these relations are not an "ontological free lunch". Therefore, at least irreducible relations must have the same ontological status as their monadic rivals, the properties. Of course, one could even suppose that relations are independent of concrete instantiations, like Platonists suggest for monadic properties, but this would led us to a too fundamental problem of philosophy - the debate between Platonism and nominalism - which I

\footnotetext{
${ }^{12}$ Another classical argument against the reality of relations is Bradley's famous argument of regress. If the relation $\mathrm{R}$ which holds between $a$ and $b$ were real, we would need another relation, say $\mathrm{R}^{*}$, which holds between this real entity $\mathrm{R}$ and $\mathrm{a}$, such as a relation between $\mathrm{R}$ and $\mathrm{b}$. But if $\mathrm{R} *$ is a very real entity again, $\mathrm{R} *$ need also a new relation, say $\mathrm{R} * *$, which holds between $\mathrm{R} *$ and a, like as between $\mathrm{R}^{*}$ and $\mathrm{R}$, and so on ad infinitum.
} 
prefer to avoid here.

One could suggest a further tentative argument for reality of relations. As we said above, entities are more real the more independent they are. In addition, one could also plausibly argue that an entity is more real, the more entities depend on it. Thus, God would be an ens realissimum not only because $\mathrm{He}$ is independent, but also because all other entities depend on Him. Now, when origin essentialism is correct, one could conclude that, when $a$ is the son of $b, a$ could not exist without the relation is son of $b$. Thus, ex hypothesis, $a$ is ontologically dependent on this relation. In this case, of course, dependence would be symmetric, and both entities ( $a$ and its relation to $b$ ) to the same degree real.

Many, including Russell, thought that supervenience is a criterion for unreality. But this seems to be a prejudice. To say that heat is nothing else than motion of molecules does indeed commit one to say that heat is ontologically dependent on molecules, but not to say that heat is unreal. It is interesting to note that we tend naturally to think this relation of dependence as asymmetrical (heat depends on molecules, but not conversely), although the existence of temperature is coextensive with the existence of molecules: there cannot be molecules without some motion nor molecules without any temperature (repose is a case of motion just as $0^{\circ} \mathrm{K}$ is also a temperature). Similarly, as soon as things exist, so do relations exist, too: at least relations like self-identity or difference, but also relations like as heavy as, as great as. When the objects are qualitatively different ( which is required by the Leibnizian principle of identity), there must also be some asymmetrical relations (is heavier than, is smaller than, ...). Thus, the set of all possible worlds in which things exist, coincides with the set of all possible worlds in which relations exist. Thus, in the modal interpretation of the notion of dependence, relations and things are mutually dependent and so must have the same degree of reality.

\subsection{The a posteriori approach of ontological commitment}

With the expression " a posteriori approach" I do not mean a single doctrine, but a family of approaches that have in common the contemporary gloss of delegating to total science a central role for de- 
ciding questions of existence. The two most prominent theories are, insofar as I can see, Quine's criterion for ontological commitment and Armstrong's (and Schoemaker's) a posteriori Realism.

With this approach, we learned to discuss questions of existence instead of reality of things. After all, existence is nearly a technical term. Of course, there is no agreement about it: is it a first or a second order predicate? Is there a difference between existence and subsistence? Is ontological existence nothing more than what is expressed by the quantifier? In any case, with this more technical term, philosophers now have the feeling they are making some progress on these questions.

According to Quine's famous suggestion, ontological questions should be decided by means of the ontological commitment test. The test consists on a simple procedure: to translate the sentences of our best theories into canonical logic, determine the domain of quantification required to render this translation true, and read the entity commitments of the elements of the required domain. Of course, some paraphrasing is allowed during the translation - and here lies the clue of the story. Oriented by these rules, many philosophers engaged themselves in the Quinean ontological game: (1) searching for sentences of natural science containing quantification over predicates (the Platonists), (2) trying to paraphrase these sentences without quantification over predicates (the nominalists), (3) showing that these paraphrases were not correct (the Platonists again), and so on. Thus, when we are willing to engage in this game for deciding the existence of relations, we should simply search within our best theories for sentences containing quantification over relational predicates.

The second contemporary criterion for "existence" or "reality" was proposed by Armstrong (1978). According to his "a posteriori Realism", total science has to decide about what universals there are. Like Quine, he thinks that the mere existence of predicates is not sufficient to support the conclusion that a corresponding universal must exist. And, again like Quine, science plays a decisive role in deciding the existence of (monadic or dyadic) properties. But Armstrong's criterion is not based on the determination of the domain of quantification of theories, but the question of what properties are linked in natural laws. Thus, for the particular case of relations, the 
question would simply be: are there non-monadic properties linked by natural laws?

I think that the observance of some very simple examples would suffice to show the necessity of the commitment to relations for both criteria, the Quinean and the Armstrongian. Take, e.g.:

(1) Some physical interactions between spatially distant bodies are only attractive (gravity), others both attractive and repelling (electromagnetism).

(2) Some causal connections in medicine (substances over physiological processes) are explained, others unexplained.

(3) Some alloying of metals can generate a material that is stronger than their primary elements. (e.g. steel is stronger than iron)

(4) There is probabilistic (non-deterministic) causality in quantum mechanics.

(5) Some matrimonies are recognized only in some, but not in all countries (e.g. homosexual matrimony).

(6) Some killing is morally and legally justified (e.g. in case of self-defense)

I think all these sentences to be good candidates for supporting the existence of relations. They are considered true by our total world description and (some) are linked by natural laws (others by social sciences). Moreover, they all involve quantification over a relational predicate, and no paraphrase without quantification over the relation seems available. Of course, in each case, a detailed logical analysis would be required. But even if there were such a paraphrase, a search in the field of science would yield many others candidates.

Take (1) for instance. By existence generalization we can derive that there are physical interactions between spatially distant bodies, and interaction is essentially a relation. Take (5). The marriage of two men $a$ and $b$ conducted in a country where homosexual matrimonies are legal is not recognized in another country. This does not mean that the particulars $a$ or $b$ are not officially recognized, but that $a$ is married to $b$ (the relation between $a$ and $b$ ) is not recognized. Similar analysis could be offered for the other examples. In any case, I think by observing our normal world descriptions we obtain 
enough grounds for supposing that relations are both constituents of natural laws (as Armstrong requires) and values of bounded variables of true sentences (as Quine requests).

\section{Conclusion and open questions}

At first sight, this paper could be seen as a defense of Russell's position, when I argued for irreducibility, externality and reality of - not of all, but of any - relations. Nevertheless, my ontological approach contrasts radically with Russell's logical approach. For Russell, relations are external and real because they are irreducible, i.e. irreducibility, reality and externality are equivalent features of relations. I argued here, in contrast, in favour of the thesis that relations can be external and real independently of being irreducible.

One important methodological conclusion I think we should draw from this analysis is that philosophers are all too fast in concluding general claims based on too few examples. In Wittgenstein's words "A main cause of philosophical disease - a one-sided diet: one nourishes one's thinking with only one kind of example" (PI § 593). When I am right, some philosophers (including Leibniz, Mugnai and Heil) failed to correctly understand relations due to nourishing their thinking with only one kind of examples.

Guido Imaguire Federal University of Rio de Janeiro and LanCog Group

\section{References}

Brower, J. 2009. Medieval Theories of Relation. In Stanford Encyclopedia of Philosophy.

http://plato.stanford.edu/search/searcher.py?query=medieval+relations

Burkhardt, H. Anmerkungen zur Logik, Ontologie und Semantik bei Leibniz. Studia Leibniziana, Band VI, Heft 1, Franz Steiner, Wiesbaden, 1974.

Clatterbaugh, K.C. 1973. Leibniz's Doctrine of Individual Accidents. Studia Leibniziana, 4, Wiesbaden.

Cover, J.A. \& O’Leary-Hawthorne. 1999. Substance and Individuation in Leibniz. Cambridge: Cambridge Univ. Press.

Hartshorne, C. 1970. Creative Synthesis and Philosophical Method. London: The SCM Press.

Horstmann, R.P. Ontologie und Relationen: Hegel, Bradley, Russell und die Kontroverse über die interne und externe Beziehungen. Königstein, Ts: Athenäum, 1984.

Imaguire, G. 2006. A Critica de Russell à Concepção Leibniziana das Relações. Manuscrito, v. 29, n. 1. 
Krikpe, S. 1972. Naming and Necessity. Oxford: Basis Blackwell.

Leibniz, G.W. Monadologie.

Leibniz, G.W. Metaphysische Abhandlung, ed. by Herrings. Hamburg: Meiner, 1991

Leibniz, G.W. Generales Inquisitiones de Analysi Notionum et Veritatum, ed. by Franz Schupp, Hamburg: Felix Meiner, 1982.

Leibniz, G.W. Die Philosophischen Schriften (GP), ed. by C.I. Gerhardt. Berlin, 1857-90. Reprint: Hildesheim: Olms, 1965.

Leibniz, G.W. Nouveaux Essais. English translation New Essais on Human Understandings, transl. and ed. by P. Remnant and J. Bennett. Cambridge: Cambridge Univ. Press, 1981.

Linsky, B. Russell's Metaphysical Logic. Stanford: CSLI Publications.

Linsky, B. The Metaphysics of Logical Atomism. In The Cambridge Companion to Bertrand Russell, ed. by N. Griffin. Cambridge: Cambridge University Press, 2003.

Moore, G. 1919. External and Internal Relations. Proceeding of the Aristotelian Society 20:40-62. Reprint in Philosophical Studies, London: K. Paul, Trench, Trubner \& Co: New York: Harcourt, Brace \& Co., 1992, pp. 276-309.

Mugnai, M. 1992. Leibniz' Theory of Relations. Studia Leibnitiana Supplementa. Stuttgart: Franz Steiner Verlag.

Mulligan, K. 1998. Relations - Through Thick and Thin. Erkenntnis 48: 325-353.

Parkinson, G.H.R. 1965. Logic and Reality in Leibniz's Metahysics. Oxford: Oxford Univ. Press.

Rescher, N. 1967. The Philosophy of Leibniz. New York, Englewood Cliffs.

Russell, B. An Analysis of Mathematical Reasoning. 1898. In Collected Papers 2.

Russell, B. The Philosophy of Logical Atomism [PLA] 1918. In Logic and Knowledge.

Russell, B. Analytic Realism [AR] 1911. In Collected Papers 3.

Russell, B. The Basis of Realism [BR] 1911. In Collected Papers 3.

Russell, B. My Philosophical Development [MPD] 1959. London: Routledge, 1993.

Russell, B. The Principles of Mathematics [PoM] 1903. London: Routledge, 1992.

Russell, B. Logical Atomism [LA] 1924. In Logic and knowledge. London: George Allen and Unwin, 1956.

Russell, B. A Critical Exposition of the Philosophy of Leibniz [PL] 1900. London: Routledge, 1992.

Russell, B. The Nature of Truth [TNT] 1905. In Collected Papers 4.

Sleight, R. C, Jr. 1900. Leibniz and Arnauld: A Commentary on Their Correspondence. New Haven: Yale University Press, 1990.

Sprigge, T. L. S. 1973. The Vindication of Absolute Idealism. Edinburgh: Edinburgh University Press.

Wittgenstein, L. 1953. Philosophical Investigations. Ed. by G.E.M. Anscombe and R. Rhees. Transl. by G.E.M. Anscombe. Oxford: Blackwell. 